\title{
Symulakryczna prywatnośé w mediach płynnej nowoczesności
}

\section{Simulacratic Privacy in the Liquid Modernity Media}

Mass Media, as one of the emanations of new information technologies, strongly affect the process of shaping individual identity, enabling creation, selection and evaluation of social and cultural patterns. As a result of progressing convergence and mediatisation, hitherto stable values have been "liquefied", and community categories have been replaced by individual ones. One example of these transformations are changes in the perception of privacy. Under the conditions of the new media ecosystem, this enduring construct, despite its own discursiveness, becomes susceptible to changes and, as Zygmunt Bauman puts it, "momentary". The purpose of this article is to capture the shifts within the dichotomous relationships that shape the meaning of privacy, which are caused by the binary structure of the media focused on satisfying individual needs. Based on the analysis of privacy in the media, defined through bipolar oppositions of private-public, authentic-intentional, relevant-irrelevant and allowed-illegitimate, the labile and simulacratic nature of privacy is revealed.

Keywords: privacy, liquid modernity, new media, identity, simulacra

Determinizm technologiczny, czyli warunkowanie odbioru i definiowania otaczającej rzeczywistości przez pryzmat oraz za pomocą środków masowego komunikowania, to jedna z klasycznych koncepcji tłumaczących społeczne oddziaływanie mediów. Marshall McLuhan zamknął jej istotę w metaforycznej definicji "The Medium is the Message"1, ujmując w zawoalowany sposób siłę, z jaką media wpływają na percepcję świata przez audytorium. To instrumentalne podejście zawiera w sobie jednak pewną niedogodność. Człowiek zostaje w nim podporządkowany dyktatowi przekaźników, które to urządzenia zostały przez niego wytworzone. Zawładnięta zostaje przy tym nie tylko jego fizyczność (ciało i zmysły), lecz także skrywana pod nią tożsamość. Okazuje się, że nawet tak konstytutywna dla samookreślenia jednostki kategoria jak prywatność, rozpatrywana w naturalnej opozycji względem sfery publicznej, w relacji dominujące media - bierne społeczeństwo może zostać zachwiana, a następnie przefiltrowana

1. Marshall McLuhan, Understanding Media The Extensions of Man (Cambridge, MA; London: The MIT Press, 1994), 7. 
przez strukturę przekaźnika pośredniczącego w jej transmisji. Wariantywne technologie cyfrowe dywersyfikują bowiem modele intymności, czyniąc z nich byty modalne, wybieralne i ulotne, a ponadto funkcjonujące poza tradycyjnie pojmowaną czasoprzestrzenią ${ }^{2}$. Identyfikacja prywatności indywiduum w mediach traci przez to swój uniwersalny wymiar, stając się po raz kolejny przedmiotem namysłu teoretycznego.

Kategoria prywatności w mediach może być analizowana przez pryzmat czterech podstawowych pól tematycznych: (1) pola definicji, którego nadrzędnym celem jest ustalenie przebiegu linii rozdzielającej to, co prywatne od tego, co publiczne; (2) pola teorii, które systematyzuje ustalenia na temat prywatności, ujmując jej rolę, istotę i formy koegzystencji zinnymi ideami; (3) pola etyki, czyli moralności zachowań komunikacyjnych manifestujących, charakteryzujących lub oceniających wcześniej zdefiniowaną prywatność; oraz (4) pola krytyki wartości, sprowadzającego się do negacji zastanego porządku społecznego, kulturowego i prawnego, a także podnoszonych w ramach tego zaprzeczenia głosów o konieczności przedefiniowania albo całkowitego porzucenia koncepcji prywatności³. Za pozorną odrębnością tych przestrzeni badawczych skrywa się jednak pewne inicjalne, wspólne wszystkim podejściom założenie, zgodnie z którym prywatność to żywy konstrukt, umiejscowiony na przecięciu kilku dychotomicznych, a zarazem wewnętrznie niestabilnych idei. Poza wspomnianą wyżej opozycją pomiędzy prywatnym a publicznym w kontekście mediów będą ją jeszcze definiować, między innymi, relacje pomiędzy spontanicznością i autentycznością a intencyjnością czy związane bezpośrednio z procesem komunikowania masowego relacje pomiędzy podmiotem a przedmiotem komunikacji, niską a wysoką istotnością oraz swobodą wypowiedzi i jej ograniczeniem. Pary te czynią z prywatności kategorię o charakterze procesualnym, której kluczowymi cechami stają się dialektyczność, niemonotoniczność oraz wielozadaniowośćt. Przede wszystkim zaś, jak ujmuje to Daniel J. Solove, prywatność staje się przez nie rozległą koncepcją (ang. sweeping concept), zależną od kultury i czasu, a przez to wymykającą się jednoznacznym i niezmiennym deskrypcjom ${ }^{5}$.

2. Por. Zygmunt Bauman, "O tarapatach tożsamości w ciasnym świecie”, Er(r)go. Teoria Literatura - Kultura, nr 6, 2003, 16.

3. Christopher T. Anglim, "Philosophical Basis of Privacy", w: Privacy Rights in the Digital Age, red. Christopher T. Anglim, Jane E. Kirtley, Grether Nobahar. (Amenia, NY: Grey House Publishing, 2015), 404.

4. Małgorzata Majewska, Prywatność a media. Zarys problematyki (Kraków: Wydawnictwo ToC, 2018), 49-50.

5. Daniel J. Solove, Understanding Privacy (Cambridge, London: Harvard University Press, 2008), 1, 50. 
Przyjmując koncepcję płynnej nowoczesności ${ }^{6}$, można tę konstatację jeszcze rozszerzyć. Prywatność w rzeczywistości miękkiego kapitalizmu jest bowiem nie typowym tworem wspólnotowym (wspólnie wypracowanym i powszechnie respektowanym), ale wynikiem zestawienia tworów jednostkowych. W środowisku społecznym, w którym ludzie zostają zmuszeni do samodzielnego wybierania wzorów wartości z ciągle rozwijającego się wachlarza dostępnych propozycji, jednostki zostają skazane na wieczne testowanie oraz zmienianie opinii o wcześniejszych wyborach w poszukiwaniu tych najbardziej satysfakcjonujących ${ }^{7}$. Co więcej, odpowiedzialność za podjęte przez nie decyzje ma również charakter osobniczy: "w świecie złożonym z jednostek istnieją tylko inne jednostki, od których możesz się uczyć, jak dbać o własne sprawy, ponosisz jednak pełną odpowiedzialność za skutki tego, że zaufałeś właśnie tej, a nie innej strategii”" Prywatność, zgodnie $\mathrm{z}$ terminologią Zygmunta Baumana, staje się przez to "momentalna", stale zanikająca i odradzająca się w cieniu jednostkowego, bezzwłocznego "spełnienia"

Wraz z następującymi po sobie kolejnymi etapami rozwoju mediów cyfrowych, postępującymi procesami ujednolicania i autonomizacji oraz zachodzącymi w ich wyniku zmianami sposobów porozumiewania się, takimi jak upowszechnienie się zindywidualizowanego komunikowania masowego ${ }^{10}$, opisywanemu "upłynnieniu" ulegają też coraz wyraźniej dychotomie indukujące prywatność. Współczesne technologie informacyjne skutecznie zakłócające ich oczywistość i niepodważalność, czynią z nich byty równie dyskursywne, co sama kategoria prywatności ${ }^{11}$. I choć stwierdzenie to nie nosi znamion oryginalności, w kontekście wzrastającej performatywności komunikowania zapośredniczonego przez media, jak i autokomunikowania przez te same media katalizowanego, identyfikacja tych semiologicznych, a niekiedy też ontologicznych przesunięć jest potrzebą niezmiennie aktualną. Zgodnie z istotą "wędrujących pojęć" Mieke Bal ${ }^{12}$ uchwycenie momentów "stawania się" poszczególnych kategorii prywatności w ich kontekście czasoprzestrzennym stanowi bowiem podłoże dla ich kolejnych (re)interpretacji - pewnego rodzaju przegląd lub diagnozę ich społecznej adekwatności i zrozumiałości.

6. Zygmunt Bauman, Płynna nowoczesność, przeł. Tomasz Kunz (Kraków: Wydawnictwo Literackie, 2006).

7. Bauman, Płynna nowoczesność, 14-15.

8. Bauman, Plynna nowoczesność, 48.

9. Bauman, Płynna nowoczesność, 184.

10. Manuel Castells, Władza komunikacji, przeł. Jakub Jedliński, Paweł Tomanek (Warszawa: Wydawnictwo Naukowe PWN, 2013), 74-81.

11. Por. Helen Nissenbaum, Privacy in Context. Technology, Policy, and the Integrity of Social Life (Stanford: Stanford Law Books, 2010), 116-117, 189.

12. Mieke Bal, Wędrujące pojęcia w naukach humanistycznych, przeł. Marta Bucholc (Warszawa: Narodowe Centrum Kultury, 2012). 
Jako pierwsza rozbita zostaje konstytutywna opozycja: prywatne - publiczne. Media sieciowe z przypisaną im technologiczną otwartością oraz responsywnością zapośredniczających ją interfejsó $w^{13}$ zmieniają znaczenie intymności i sposobów jej ochrony. Coraz częściej za cenę własnej wygody oraz gratyfikacji wynikającej $\mathrm{z}$ natychmiastowej realizacji potrzeb komunikacyjnych użytkownicy skłonni są rezygnować z pewnego poziomu kontroli nad jawnością prywatnych informacji14. Zakres utraconej przez nich sprawczości jest tym większy, im więcej czasu dany użytkownik spędza w cyberprzestrzeni ${ }^{15}$ oraz im mniej jest on świadomy celów i sposobów przetwarzania jego danych przez skrywane za przyjaznym layoutem binarne algorytmy systemów informatycznych.

Dotychczas pilnie strzeżone sekrety lub treści dostępne wyłącznie wąskiemu gronu rodziny i przyjaciół w wyniku jednego kliknięcia, przypadkowego lub zaplanowanego, mogą zostać w ułamku sekundy zanurzone w sferze publicznej. Przez unifikujące cechy kodu binarnego ${ }^{16}$, nawet wówczas, gdy treści nie stają się stricte publiczne, tzn. nie są odbierane przez szerokie i w zdecydowanej większości zanonimizowane audytorium, są kodowane i dekodowane w ekosystemie, który został oparty na idei powszechnej jawności i dostępności, co znacząco utrudnia sprawowanie nad nimi rzeczywistej kontroli. Na przykład fotografie osadzane w prywatnym dyskursie cyfrowym tracą intymny charakter, ponieważ transkodowane na język nowych mediów, z konstytutywną dla niego wariantywnością i modularnością, odrywają się od podmiotów, do których należały i które to podmioty przedstawiały, równocześnie stając się e-treściami podatnymi na wtórne odczytania oraz przetworzenia - modyfikacje te nie muszą przy tym pokrywać się z wolą nadawców, właścicieli fotografii. Kluczowe w zaprezentowanym przykładzie jest jednak to, że na poziomie świadomości przeprowadzana wymiana może zachowywać charakter prywatny, ponieważ wskazywana technologia z jej “upłynniającymi” prywatność właściwościami pozostaje dla większości użytkowników transparentna.

Struktura mediów, w których centrum umiejscowiona zostaje osoba użytkownika i przynależne jej potrzeby komunikacyjne, dodatkowo narusza znaczenie

13. Piotr Celiński, Interfejsy. Cyfrowe technologie w komunikowaniu (Wrocław: Wydawnictwo Uniwersytetu Wrocławskiego, 2010), 173.

14. Jane E. Kirtley, "Introduction”, w: Privacy Rights in the Digital Age..., XXI; Andrzej Poszewiecki, Wojciech Bizon, "Measurement of Privacy by Using an Experiment", w: Looking through an Economic Keyhole - Privacy Matters, red. Andrzej Poszewiecki (Gdańsk: Uniwersytet Gdański, 2016), 60.

15. Daniel J. Solove, The Future of Reputation. Gossip, Rumor, and Privacy on the Internet (Londyn: Yale University Press, 2007), 9.

16. Piotr Celiński, Postmedia. Cyfrowy kod i bazy danych (Lublin: Wydawnictwo Uniwersytetu Marii Curie-Skłodowskiej, 2013), 17. 
autentyczności i spontaniczności w procesach wypracowywania jednostkowego znaczenia prywatności. Obserwowany przez Philippe’a Lejeune’a wzrost zainteresowania diarystyką związany ze zwiększeniem dostępności komputerów osobistych ${ }^{17}$, potwierdzony późniejszą ekspansją blogosfery ${ }^{18}$, a także medialna dostępność intymności ${ }^{19}$, w platformach społecznościowych tylko przybrały na sile. Pozornie niewidoczna i neutralna technologia sieci, która z personalizacji uczyniła swoją drogę rozwoju, skłania internautów do jeszcze bardziej narcystycznych zachowann ${ }^{20}$. W głównych polach optycznych szablonów graficznych tych portali zamieszczone zostają elementy, które zachęcają odbiorców do dzielenia się własnymi przeżyciami: edytory tekstu sygnalizujące konieczność wprowadzenia własnych danych oraz przeglądy najnowszych treści udostępnionych przez inne osoby, które są powiązane z użytkownikiem i niejako w wyniku tego powiązania powinny wzbudzić jego zainteresowanie. Skuteczność perswazyjnych zabiegów wizualnych jest oczywiście różna i, jak się wydaje, zależna od celu komunikacyjnego sprzęgniętego $\mathrm{z}$ typem osobowości nadawcy - naturalnie będzie ona wyższa u osób traktujących media społecznościowe jako miejsce spełniania potrzeb szacunku i uznania oraz samorealizacji, a niższa u internautów odnajdujących w nich przestrzeń realizacji indywidualnych praktyk voyeurystycznych czy jednokierunkowe źródło informacji.

Nastawienie na autobiografizm w interaktywnych platformach, bez względu na stopień samoupublicznienia podmiotu, przypomina sygnalizowane wcześniej testowanie wzorców wartości w celu oceny ich społecznej użyteczności oraz aktualności. Jest też szybkim sposobem urzeczywistniania bytów i przeżyć, które w momencie upowszechnienia odzyskują zatraconą w cyberprzestrzeni realność i atrakcyjnośćc ${ }^{21}$. Publikacje tego typu uzmysławiają jednak przede wszystkim, że tak jak w przypadku każdej innej działalności diarystycznej tworzenie prywatnych zapisków z myślą o ich publicznym udostępnieniu, nawet wąskiemu i zaufanemu gronu odbiorców, znosi ich bezdyskusyjny autentyzm. Pierwotnie autoteliczna aktywność w momencie rozpowszechnienia poprzez media społecznościowe przeobraża się w aktywność intencjonalną, która mimo zawarcia

17. Philippe Lejeune, “Drogi zeszycie...”, “drogi ekranie...”: o dziennikach osobistych, przeł. Agnieszka Karpowicz, Magda i Paweł Rodakowie (Warszawa: Wydawnictwo Uniwersytetu Warszawskiego, 2010).

18. Marta Więckiewicz, Blog w perspektywie genologii multimedialnej (Toruń: Wydawnictwo Adam Marszałek, 2012), 55-57

19. Brian McNair, Seks, demokratyzacja pożądania i media, czyli kultura obnażania, przeł. Ewa Klekot (Warszawa: Warszawskie Wydawnictwo Literackie MUZA, 2004), 15.

20. Magdalena Szpunar, "Koncepcja bańki filtrującej a hipernarcyzm nowych mediów", Studia Medioznawcze, tom 61, nr 2, 2018, 193-194.

21. Bauman, Płynna nowoczesność, 131. 
Lajeunowskiego paktu autobiograficznego ${ }^{22}$ umożliwia diaryście ingerowanie w przekaz nie tylko przed jego udostępnieniem innym użytkownikom (autocenzura prewencyjna), ale dzięki narzędziom edycji umożliwiającym wprowadzanie zmian w czasie rzeczywistym także po tym fakcie (autocenzura post factum). Ślady prywatnego "ja" pozostawiane w zapiskach pamiętnikarskich w wyniku oddziaływania technologii mogą być więc nieustannie filtrowane i ewaluowane, a w konsekwencji modyfikowane i usuwane. Jeśli dołączymy do tego możliwość różnicowania przekazów eksponujących prywatność w różnych przestrzeniach społecznościowych, to określająca jednostkę sfera prywatna traci wykształcone dystynkcje, stając się niczym tożsamość tworem sieciowym ${ }^{23}$.

Zobrazowana sytuacja zmienia się, gdy rozważania nad intencyjnością emanacji prywatności w mediach zostaną przeniesione z mediów społecznościowych i oddolnych na instytucjonalne media głównonurtowe, które są podporządkowane odredakcyjnym oraz prawnym regułom selekcji i dystrybucji treści. To przesunięcie stawia w centralnym miejscu już nie tylko pytanie o autentyzm wiadomości o prywatności jednostki, ale również pytania o społeczną istotność oraz o legalność tego typu materiałów.

Media masowe, funkcjonujące w rygorze międzynarodowego i krajowego porządku prawnego, są zmuszone do stałego wypracowywania równowagi pomiędzy istotnością a brakiem znaczenia rozpowszechnianych treści oraz swobodą wypowiedzi i jej ograniczaniem. Po ukierunkowaniu pracy redakcji na dostarczanie materiałów typu human interest stories, wywołanym przez nowe technologie zwiększające pojemność przestrzeni komunikacyjnej do wymiarów uniemożliwiających jej zapełnienie wyłącznie pełnowartościowymi oraz znaczącymi treściami ${ }^{24}$, niegdysiejsza, wyraźnie umocowana w tradycji dziennikarskiej teoria wartości informacji Johana Galtunga i Mari Holmboe Ruge ${ }^{25}$ czy bardziej współczesne założenia "newsowości" przedstawione przez Yvonne Jewkes ${ }^{26}$ tracą swoją siłę wyrazu. Głównym celem rozpowszechnianych przekazów nie jest już bowiem

22. Philippe Lejeune, "Pakt autobiograficzny", w: Wariacje na temat pewnego paktu. O autobiografii, przeł. Wincenty Grajewski, Stanisław Jaworski, Aleksander Labuda, Regina Lubas-Bartoszyńska (Kraków: Universitas, 2001), 21-56.

23. Martin Lister, Jon Dovey, Seth Giddings, Ian Grant, Kieran Kelly, Nowe media. Wprowadzenie, przeł. Marta Lorek, Agata Sadza, Katarzyna Sawicka (Kraków: Wydawnictwo Uniwersytetu Jagiellońskiego, 2009), 400; por. Darin Barney, Społeczeństwo sieci, przeł. Marcin Fronia (Warszawa: Wydawnictwo Sic!, 2008), 174-181.

24. Ellis Cashmore, Celebrity/Culture (Abingdon: Routledge, 2006), 54-55.

25. Johan Galtung, Mari Holmboe Ruge, “The Structure of Foreign News The Presentation of the Congo, Cuba and Cyprus Crises in Four Norwegian Newspapers", Journal of Peace Research, tom $2, \mathrm{nr} 1,1965,65$.

26. Yvonne Jewkes, Media i przestępczość, przeł. Ewa Magiera (Kraków: Wydawnictwo Uniwersytetu Jagiellońskiego, 2010), 40-61. 
wiarygodne opisywanie oraz tłumaczenie otaczającej ludzi rzeczywistości, ale informowanie odbiorców o istnieniu niektórych problemów i wytworzenie z nimi krótkotrwałej wspólnoty ${ }^{27}$. Świat najlepiej jest zatem opisywać nie przez pryzmat konkretnych wydarzeń, ale przez pryzmat ludzkich przeżyć, zwłaszcza jeśli przeżycia te należą do gwiazd i celebrytów ${ }^{28}$. Tymczasem oceny społecznej użyteczności oraz atrakcyjności materiałów upubliczniających cudzą prywatność nie da się przeprowadzić na podstawie dawnych kryteriów formalnych. Toteż coraz częściej przybiera ona charakter moralny.

Anurag Pareek i Arka Majumdar wskazywali, że najważniejszą potrzebą staje się w tym kontekście określenie różnicy pomiędzy "tym, co jest przedmiotem publicznego zainteresowania, a tym, czym interesuje się publiczność" 29 . Dlatego w nowych warunkach komunikowania masowego elementami znaczącymi medialną istotność treści voyeurystycznych mogą stać się także wykorzystywane przez prawników kryteria: przestrzeni - o legalności publikacji decyduje to, w jakim miejscu uchwycona została prywatność jednostki ${ }^{30}$; kręgów społecznych w których kluczowe znaczenie ma, czy ujawniające szczegóły życia prywatnego materiały były przeznaczone wyłącznie dla najbliższych ${ }^{31}$; celu - stawiające pytanie o to, czy cudzą prywatność udostępniono dla rozrywki, czy dla dobra społeczeństwa $^{32}$. Niemniej, w środowisku mediów sieciowym wymienione wyznaczniki nie są już tak stabilne, jak w mediach tradycyjnych. Przestrzeń, w której uchwycona zostaje prywatność, może być jednocześnie prywatna i publiczna. Osoba, która odbiera intymne e-treści, jej wiarygodność oraz towarzyszące jej intencje nie mogą być szybko zweryfikowane ze względu na sieciową konstrukcję jej tożsamości. Wreszcie, wraz z upływem czasu cel upublicznienia poprzez fizyczne oderwanie od nadawcy i pierwotnego kontekstu może się zmienić, przeformułować legalność medialnych przetworzeń. W skrajnym ujęciu, przy całkowitym rozchwianiu semantycznym tych kryteriów, dychotomia pomiędzy brakiem a wysoką istotnością przekazów o życiu prywatnym mogłaby zatem zaniknąć, stać się ulotnym wytworem sytuacji komunikacyjnej. Choć dostosowywany do warunków technologicznych i społecznych system prawny uniemożliwia

27. Bauman, Płynna nowoczesność, 107.

28. Cashmore, Celebrity/Culture, 26, 34.

29. "[...] distinguish between what is public interest and what the public is interested in". Anurag Pareek, Arka Majumdar, "Protection of Celebrity Rights - The Problems and the Solution", Journal of Intellectual Property Rights, tom 11, 2006, 419.

30. Kim McNamara, "Publicising Private Lives: Celebrities, Image Control and the Reconfiguration of Public Space”, Social \& Cultural Geography, tom 10, nr 1, 2009, 19.

31. Solove, The Future of..., 178; Solove, Understanding..., 48.

32. Raymond Wacks, Privacy. A Very Short Introduction (Oxford, New York: Oxford University Press, 2010), 48. 
realizację tego scenariusza, $\mathrm{w}$ dyskusjach teoretycznych coraz częściej podnoszone są głosy o konieczności indywidualizacji rozstrzygnięć dotyczących naruszeń prywatności w mediach ${ }^{33}$.

Wzrastające znaczenie jednostkowości kieruje nas w kierunku ostatniej bipolarnej opozycji rozciągającej się pomiędzy podmiotami a przedmiotami medialnych narracji o prywatności. Mając na uwadze rozpoznawalność i role społeczne pełnione przez osoby, których prywatność jest przedmiotem eksploracji mediów, większość dyskursów koncentruje się na prezentacji życia prywatnego osób publicznych. Sprawowany urząd, jak również osiągnięta lub odziedziczona przez daną osobę popularność, w myśl zasady volenti non fit iniuria, są traktowane równoznacznie z czynnikami znoszącymi prawo tej osoby do prywatności ${ }^{34}$. Sama prywatność staje się przez to kreacją - czymś nie do końca prawdziwym, bo dającym się zarządzać i mogącym stanowić przedmiot wymiany na wolnym rynku. Tymczasem cyfrowe platformy komunikacyjne w wyniku zaprzeczenia inicjalnej opozycji prywatne - publiczne rozszerzają grono nadawców i obiektów zainteresowania mediów o osoby niebędące w myśl prawa postaciami publicznymi. Technologia znosząca dystans komunikacyjny i umożliwiająca anonimizację prowadzonej wymiany informacji wywołuje wrażenie społecznego bezpieczeństwa, czym skłania użytkowników do przekraczania utrzymywanej w świecie realnym granicy pomiędzy tym, co wypada mówić publicznie, a tym, co powinno pozostać treścią niejawną.

W sytuacji, w której każdy użytkownik sieci może stać się aktywnym uczestnikiem dyskursu o cudzej lub/i własnej prywatności bądź dyskurs ten tworzy sama technologia, reguły i kryteria upubliczniania życia intymnego jednostek w mediach rozmywają się. Dotychczasowy porządek prawny, który zakładał dbanie o szeroko rozumiane dobro odbiorców, w tym nierozpowszechnianie informacji na temat ich życia prywatnego, nie daje jednoznacznych odpowiedzi odnośnie do legalności aktywności nadawczo-odbiorczych naruszających tę sferę. Kluczowa względem tych rozstrzygnięć wydaje się dlatego wolicjonalność obiektu, którego prywatność zostaje ujawniona, a także umiejętności medialne (ang. media literacy) oraz świadomość medialnego nadzoru ${ }^{35}$. Jako jedyne są one bowiem w stanie

33. Wacks, Privacy..., 4.

34. Wiesław Godzic, Anna Buchner, Małgorzata Kubalska, Lidia Rudzińska-Sierakowska, Celebryci w polskiej przestrzeni medialnej i społecznej. Badanie interdyscyplinarne (Warszawa: Uniwersytet SWPS, 2019), , 119-120. https://www.swps.pl/images/Raport_celebryci.pdf (16.06.2020); Claire E. Gorman, "Publicity and Privacy Rights: Evening out the Playing Field for Celebrities and Private Citizens in the Modern Game of Mass Media", DePaul Law Review, tom 53, nr 3, 2004, 1258.

35. Johanna E. Möller, Jakub Nowak, "Surveillance and Privacy as Emerging Issues in Communication and Media. An introduction", Mediatization Studies, tom 2, 2018, 13. 
określić, czy planowane albo dokonane upublicznienie prywatnych wiadomości jest zgodne z wolą podmiotu, którego dotyczy dany akt komunikacyjny.

Zasygnalizowane "upłynnienie" dychotomii określających prywatność w nowomedialnym ekosystemie czyni prywatność kategorią przynależną Baudrillardowskiemu porządkowi symulakrów symulacji ${ }^{36}$. Wzrastająca w wyniku przeobrażeń technologicznych i społeczno-kulturowych dyskursywność oraz indywidualizacja terminów tworzących bipolarne opozycje pomiędzy prywatnym i publicznym, spontanicznością i autentycznością a intencyjnością oraz podmiotem i przedmiotem komunikacji uniemożliwiają dalsze stosowanie porównań w celu wytwarzania sensu. Dystans dzielący graniczne elementy tych opozycji zostaje skrócony, a w niektórych przypadkach całkowicie wchłonięty. Znaczenie tych terminów może być przez to coraz swobodniej interpretowane, a prawdziwość każdej z tych jednostkowych interpretacji - "wymienialna". Takie ujęcie prowadzi do poniekąd oczywistego wniosku o labilności prywatności w mediach, której efektem jest zwielokrotnienie i współwystępowanie wielu, niekiedy sprzecznych, definicji.

Semantyczna różnorodność określeń prywatności oddziałuje na społeczne, kulturowe i prawne uwarunkowania komunikacji zapośredniczonej przez media. Kiedy każda interpretacja prywatności oraz stojących za nią dychotomia jest poprawna, jednoznaczne określenie zasadności i legalności podejmowanych akcji interlokucyjnych wydaje się zadaniem skazanym na niepowodzenie, co potwierdzają wskazywane przez prawoznawców problemy jurysdykcyjne ${ }^{37}$. W zależności od intencji komunikacyjnych oraz sytuacji, w której ujawniona zostaje prywatność $\mathrm{w}$ mediach, a także $\mathrm{z}$ uwagi na uwarunkowania podmiotu i obiektu dyskursu ocena kwalifikowanego aktu może być inna. Architektura platform sieciowych jeszcze tę niespójność pogłębia, ponieważ umożliwia ona dzielenie treści medialnych na niezależne części, posiadające inną budowę, autorstwo, a niekiedy również inny czas udostępnienia. Powstałe w ten sposób cząstki zostają pozbawione pierwotnego znaczenia i przynależnego mu kontekstu, równocześnie zachowując swój symboliczny potencjał. Zinterpretowane osobno mogą nieść całkowicie odmienne sensy o dyskusyjnej względem pierwotnego komunikatu prawdziwości.

Tym samym jedna spójna prywatność zostaje w mediach podzielona na wiele równoważnych wariantów, uwarunkowanych różnymi czynnikami i podlegających różnym ocenom. Ten wielowariantowy konstrukt funkcjonuje w płynnej, fragmentarycznej i pełnej "nie-miejsc" rzeczywistości, w której zapośredniczony

36. Jean Baudrillard, Symulakry i symulacja, przeł. Sławomir Królak (Warszawa: Wydawnictwo Sic!, 2005), 149-150.

37. Anna Banaszewska, "Prawo do prywatności we współczesnym świecie”, Białostockie Studia Prawnicze, tom 13, 2013, 32. 
przez technologię sens zostaje zastąpiony symulakrą. W środowisku zduplikowanych tożsamości, w którym prawdziwe “ja” (a wraz z nim prawdziwa prywatność) nie jest niczym jednorodnym ani stałym, $\mathrm{w}$ którym treści moralnie dobre i złe są zapisane tym samym kodem, omawiana kategoria jest nieustannie dekonstruowana. Zaobserwowana złożoność może zachęcać uczestników komunikacji do patrzenia na prywatność w mediach tylko z perspektywy indywidualnych potrzeb w oderwaniu od społecznych, kulturowych i prawnych regulacji, określających związane z nią przywileje i obowiązki. Chociaż, jak zauważa Bauman, jej upublicznienie, a w tym przypadku także rozczłonkowanie, nie zmienia jej istoty - prywatność pozostaje prywatnością ${ }^{38}$.

Medialne "okno", które w naturalny sposób oddzielało domowy, wewnętrzny świat jednostki od obserwowanych przez nie nieustannie zmieniających się sekwencji społecznych obrazów, w momencie "upłynnienia" przekaźników zostało uchylone, a dotychczas rozdzielane przez nie sfery życia uległy dyfuzji. Otwarta na interpretację prywatność, choć dająca się zdefiniować, stała się przez to jeszcze bardziej dyskursywna. Dostępne i transparentne technologie informacyjne rozchwiały tworzące ją sensotwórcze opozycje, czyniąc z nich kategorie poddające się procesom indywidualizacji oraz ewaluacji. Ich istotowość stała się "momentalna" i podatna na modyfikacje. Rozgraniczające znaczenia prywatnego i publicznego "okno" w mediach płynnej nowoczesności zaczyna się przez to coraz bardziej upodabniać do Baudrillardowskiego lustra, w którym równocześnie mogą się odbijać realne i pozorne, trwałe i ulotne, osadzone w tradycji i doraźne obrazy prywatności. Medialna machina w wyniku przyspieszenia obiegu informacji przestaje jednak te reprezentacje selekcjonować, pozostawiając ostateczny wybór jednostce, która - zmuszona do stałego redefiniowania swojej usieciowionej tożsamości - musi podjąć decyzję, gdzie i jak przebiega jej osobista linia podziału pomiędzy prywatnym a publicznym, licząc na to, że dokonany przez nią wybór będzie się wpisywał we wzorce przyjęte przez jego wirtualną wspólnotę.

Gdy wszystkie definicje prywatności i tworzące je kategorie zostają technologicznie zrównane do roli neutralnych danych, a następnie zanurzone w oceanie cyfrowych informacji, każda próba ich samodzielnej redefinicji jest jednak jedynie chwilowa - ważna wyłącznie teraz, w tym miejscu i czasie, przypadkowa - stworzona na podstawie tego, co znane i dające się zrozumieć, a przede wszystkim obarczona doświadczeniami i emocjami tworzącej ją osoby. Zapośredniczona przez media prywatność jest dziś dlatego jeszcze bardziej niejednorodna, a zarazem (ze względu na swoją nieuchwytność) coraz bardziej istotna. Obserwacja ta, choć oczywista, powinna skłaniać do nieustannej rewizji tego "wędrującego pojęcia”. Dynamiczna technologia, która zmienia społeczne i kulturowe protokoły

38. Bauman, Płynna nowoczesność, 108. 
wykorzystywania mediów, oddziałuje bowiem nie tylko na pragmatykę (sposób korzystania z narzędzi cyfrowych), lecz także ontologię (przenoszone i kształtowana za pośrednictwem sieci byty). (Re)konstrukcja prywatności powinna być $\mathrm{z}$ tego względu procesem ciągłym, równocześnie diagnozującym aktualność zastanych koncepcji, jak również identyfikującym zachodzące w ich obrębie przeobrażenia. 


\section{Bibliografia}

Anglim, Christopher T., Jane E. Kirtley, Gretchen Nobahar, red. Privacy Rights in the Digital Age. Amenia, NY: Grey House Publishing, 2015.

Bal, Mieke. Wędrujące pojęcia w naukach humanistycznych, przeł. Marta Bucholc. Warszawa: Narodowe Centrum Kultury, 2012.

Banaszewska, Anna. "Prawo do prywatności we współczesnym świecie”. Białostockie Studia Prawnicze, tom 13, 2013, 127-136.

Barney, Darin. Społeczeństwo sieci, przeł. Marcin Fronia. Warszawa: Wydawnictwo Sic!, 2008.

Baudrillard, Jean. Symulakry i symulacja, przeł. Sławomir Królak. Warszawa: Wydawnictwo Sic!, 2005.

Bauman, Zygmunt. "O tarapatach tożsamości w ciasnym świecie”. Er(r)go. Teoria - Literatura - Kultura, nr 6, 2003, 9-25.

Bauman, Zygmunt. Płynna nowoczesność, przeł. Tomasz Kunz. Kraków: Wydawnictwo Literackie, 2006.

Cashmore, Ellis. Celebrity / Culture. Abingdon: Routledge, 2006.

Castells, Manuel. Władza komunikacji, przeł. Jakub Jedliński, Paweł Tomanek. Warszawa: Wydawnictwo Naukowe PWN, 2013.

Celiński, Piotr. Interfejsy. Cyfrowe technologie w komunikowaniu. Wydawnictwo Uniwersytetu Wrocławskiego, 2010.

Celiński, Piotr. Postmedia. Cyfrowy kod i bazy danych. Lublin: Wydawnictwo Uniwersytetu Marii Curie-Skłodowskiej, 2013.

Galtung, Johan, Ruge Mari Holmboe. "The Structure of Foreign News. The Presentation of the Congo, Cuba and Cyprus Crises in Four Norwegian Newspapers”. Journal of Peace Research tom 2, nr 1, 1965, 64-90.

Godzic, Wiesław, Anna Buchner, Małgorzata Kubalska, Lidia Rudzińska-Sierakowska. Celebryci w polskiej przestrzeni medialnej i społecznej. Badanie interdyscyplinarne. Warszawa: Uniwersytet SWPS. https://www.swps.pl/images/Raport_celebryci.pdf (16.06.2020).

Gorman, Claire E. "Publicity and Privacy Rights: Evening out the Playing Field for Celebrities and Private Citizens in the Modern Game of Mass Media". DePaul Law Review tom 53. nr 3, 2004, 1247-1283.

Jewkes, Yvonne. Media i przestępczość, przeł. Ewa Magiera. Kraków: Wydawnictwo Uniwersytetu Jagiellońskiego, 2010.

Kirtley, Jane E. "Introduction”. W: Privacy Rights in the Digital Age, red. Christopher T. Anglim, Jane E. Kirtley, Gretchen Nobahar, XXI-XXVI. Amenia, NY: Grey House Publishing, 2015.

Lejeune, Philippe. Wariacje na temat pewnego paktu. O autobiografii, przeł. Wincenty Grajewski, Stanisław Jaworski, Aleksander Labuda, Regina Lubas-Bartoszyńska. Kraków: Universitas, 2001. 
Lejeune, Philippe. “Drogi zeszycie...”, “drogi ekranie...”: o dziennikach osobistych, przeł. Agnieszka Karpowicz, Magda i Paweł Rodakowie. Wydawnictwo Uniwersytetu Warszawskiego, 2010.

Lister, Martin, Dovey Jon, Giddings Seth, Grant Ian, Kelly Kieran. Nowe media. Wprowadzenie, przeł. Marta Lorek, Agata Sadza, Katarzyna Sawicka. Kraków: Wydawnictwo Uniwersytetu Jagiellońskiego, 2009.

Majewska, Małgorzata. Prywatność a media. Zarys problematyki. Kraków: Wydawnictwo ToC, 2018.

McLuhan, Marshall. Understanding Media. The Extensions of Man. Cambridge, MA; London: The MIT Press, 1994.

McNair, Brian. Seks, demokratyzacja pożądania i media, czyli kultura obnażania, przeł. Ewa Klekot. Warszawskie Wydawnictwo Literackie MUZA, 2004.

McNamara, Kim. "Publicising Private Lives: Celebrities, Image Control and the Reconfiguration of Public Space”. Social \& Cultural Geography, tom 10, nr 1, 2009, 9-23.

Möller, Johanna E., Nowak Jakub. "Surveillance and Privacy as Emerging Issues in Communication and Media. An Introduction". Mediatization Studies, tom 2, 2018, 7-15.

Nissenbaum, Helen. Privacy in Context. Technology, Policy, and the Integrity of Social Life. Stanford, CA: Stanford Law Books, 2010.

Pareek, Anurag, Majumdar Arka. "Protection of Celebrity Rights - The Problems and the Solution". Journal of Intellectual Property Rights, tom 11, 2006, 415-423.

Poszewiecki, Andrzej, Bizon Wojciech. "Measurement of Privacy by Using an Experiment". W: Looking through an Economic Keyhole - Privacy Matters, red. Andrzej Poszewiecki, 59-82. Gdańsk: Uniwersytet Gdański, 2016.

Solove, Daniel J. The Future of Reputation. Gossip, Rumour, and Privacy on the Internet. London: Yale University Press, 2007.

Solove, Daniel J. Understanding Privacy. Cambridge, MA; London: Harvard University Press, 2008.

Szpunar, Magdalena. "Koncepcja bańki filtrującej a hipernarcyzm nowych mediów”. Studia Medioznawcze, tom 61, nr 2, 2018, 191-200.

Wacks, Raymond. Privacy. A Very Short Introduction. Oxford, Nowy Jork: Oxford University Press, 2010.

Więckiewicz, Marta. Blog w perspektywie genologii multimedialnej. Toruń: Wydawnictwo Adam Marszałek, 2012. 
